\title{
A Novel Research of ZVZCS Synchronous Rectification Converter Based on Phase-shifted Full-bridge Control
}

\author{
Zhou Yongqin $^{1, \mathrm{a}}$, Huang $\mathrm{Ce}^{1}$,Chen Junjie ${ }^{1}$,Shi Guijun ${ }^{2, \mathrm{~b}}$ and Zhou Meilan ${ }^{1}$ \\ ${ }^{1}$ School of Electrical and Electronic Engineering, Harbin University of Science \\ and Technology, Harbin, China \\ ${ }^{2}$ State Grid of Ying Kou Power Supply Company, Liaoning, China \\ azyqemail@163.com, ${ }^{b} 2693718376 @ q q . c o m$
}

\begin{abstract}
Due to synchronous rectification based on Phase-shift full bridge converter is difficult to work in a state of soft switch, to solve this problem, this paper sets out an control approach of synchronous rectification based on the ZVZCS phase-shifted full-bridge, and the drive signal of synchronous rectification side uses leading-leg drive waveform after a certain time delay and applies the resonant principle in the switching process, not only keeping full bridge ZVZCS soft switching but also realizing MOSFET of the synchronous rectification ZVS. The simulation of saber and experimental research show that the converter has a good performance.
\end{abstract}

Keywords: ZVZCS converter, synchronous rectification, the simulation of saber

\section{Introduction}

With the rapid development of the contemporary technology, phase-shift full-bridge converter was highly concerned by people due to advantages like simple circuit structure, high power density power supplies and high efficiency and easy to realize soft-switching for switching devices. In low voltage and high current output situation, phase-shifted fullconverter will cause a great power loss and decrease the overall efficiency if the power supply to the voltage drop on the secondary rectifier diode. The synchronous rectification technology was introduced, using the power MOSFET with very low on-state resistance to replace the diode rectifier [1-2], in order to improve the overall efficiency of power supply under the circumstance of low voltage and high current.

ZVS was achieved in paper [3], but the synchronous rectifier was working at hard switch state. All switches ZVS was realized in synchronous rectifier converter in paper [4], but the lagging leg switches was hard to realize soft-switching when at light load situation due to the use of conventional phase-shifted full-bridge converter. In paper [5], a phase-shift full bridge ZVZCS was proposed which the leading leg switches and lagging leg switches can realize soft switch under wide scope situation, and the circuit structure is not only simple, but also low dissipation loop. Based on this, asynchronous rectifier converter control method based on phase-shift full bridge ZVZCS was proposed in this paper, it got the opposite wave of the drive wave for the leading leg switches, coupled with appropriate delay, it not only can realize ZVZCS for full bridge side of converter, but also can realize ZVS for secondary synchronous rectifier. The proposed control method add the simple circuit in traditional synchronous rectifier topology, namely realize wide range of soft switch enabled for all switches, it can further reduce the overall loss, increase the efficiency of power supply. To verify the effectiveness of the proposed converter, theoretical analysis and experimental results will be presented with $4.8 \mathrm{~kW}$ onboard charger specification. 


\section{Operation Principle for Converter}

Schematic diagram of the proposed converter is shown in figure $1 . \mathrm{Q}_{1}-\mathrm{Q}_{4}$ are ZVZCS switches for phase-shift full bridge, $\mathrm{C}_{1}$ and $\mathrm{C}_{3}$ are parallel capacitance for $\mathrm{Q}_{1}$ and $\mathrm{Q}_{3}$, $C_{1}=C_{3}=C_{r}, D_{1}$ and $D_{3}$ are anti-parallel diode for $Q_{1}$ and $Q_{3}, D_{2}$ and $D_{4}$ are serious diodes for lagging arm $\mathrm{Q}_{2}$ and $\mathrm{Q}_{4}, \mathrm{C}_{\mathrm{b}}$ is blocking capacitor, $\mathrm{L}_{\mathrm{lk}}$ is leak inductance of the transformer, $\mathrm{Q}_{5}$ and $\mathrm{Q}_{6}$ are synchronous rectifier switches. $\mathrm{L}_{5}$ and $\mathrm{L}_{6}$ are multiple frequency inductances, $\mathrm{R}$ is load, $\mathrm{C}$ is load capacitor, $\mathrm{K}$ is turns ratio for transformer, the control sequence diagram of converter is shown in Figure 2.

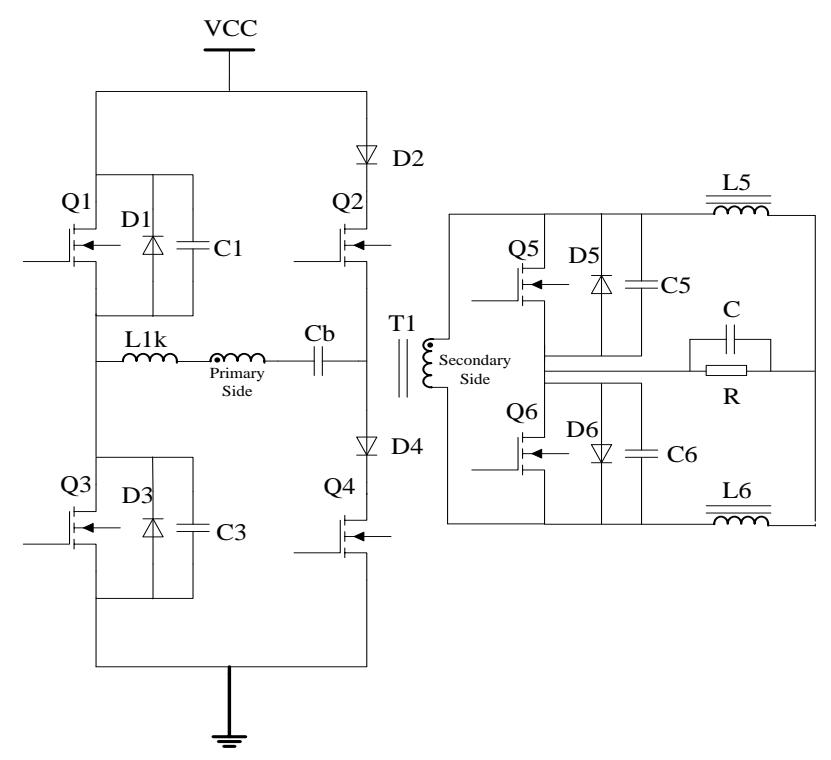

Figure 1. Schematic Diagram of the Proposed Converter

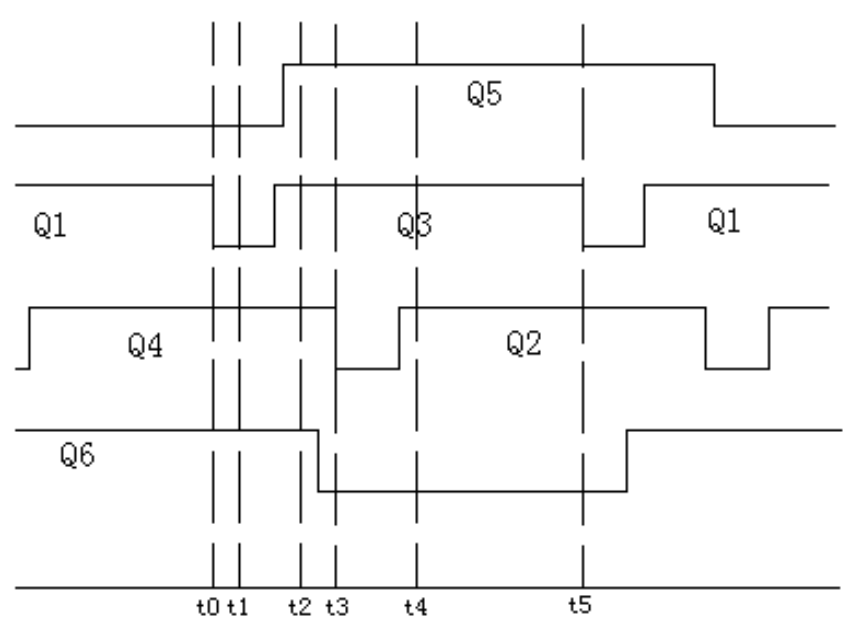

Figure 2. Key Waveforms of the Proposed Converter

(1)Mode 1( $\left.\mathrm{t}_{0}\right)$

At $t_{0}, Q_{1}$ and $Q_{4}$ are on, the current from original side flow from $Q_{1}$, blocking capacitor $\mathrm{C}_{\mathrm{b}}$, the transformer primary side, leakage inductance $\mathrm{L}_{\mathrm{kk}}$ and $\mathrm{Q}_{4}$ towards the vice side to pass the power and charge to block $\mathrm{C}_{\mathrm{b}}$ and the parasitic capacitance of $\mathrm{C}_{3}$ in the leading 
leg switches. the vice side current flow from $\mathrm{L}_{5}$, load $\mathrm{R}$ and $\mathrm{Q}_{6}$ back to the secondary side of the transformer, and to $\mathrm{C}_{5}$ charge . Another current loop $\mathrm{L}_{6}, \mathrm{R}, \mathrm{Q}_{6} . \mathrm{U}_{\mathrm{AB}}=\mathrm{U}_{\mathrm{in}}, \mathrm{U}_{\mathrm{A}}=\mathrm{U}_{\mathrm{in}}$ , $\mathrm{U}_{\mathrm{B}}=0$, the voltage value of the blocking capacitor $\mathrm{C}_{\mathrm{b}} \mathrm{U}_{\mathrm{Cb}}\left(\mathrm{t}_{0}\right)$.

(2) Mode $2\left[t_{0}, t_{1}\right]$

At $t_{0}$, turn off $Q_{1}$, capacitor $C_{1}$ begins to charge from 0 to a voltage, a voltage from the capacitor $\mathrm{C}_{3}$ starts discharging $\mathrm{U}_{\text {in }}, \mathrm{Q}_{1}$ is the zero voltage turn-off. Secondary inductance reflected to the primary series with the leakage inductance, the inductance is very great at this time, the primary current $\mathrm{i}_{\mathrm{p}}$ can be approximated seen as unchanged, $I_{p 0}=I_{0} / K$, as a constant current source, and continue to charge the blocking capacitor $\mathrm{C}_{\mathrm{b}}$ . At time $t_{1}$, the capacitor $C_{3}$ is completely discharged and has been reduced to 0 , the diode $\mathrm{D}_{3}$ will naturally be connected.

$$
\begin{aligned}
& u_{C_{0}}(t)=U_{C_{0}}\left(t_{0}\right)+\frac{I_{P_{0}}}{C_{b}}\left(t-t_{0}\right) \\
& u_{C_{1}}(t)=\frac{I_{P_{0}}}{2 C_{r}}\left(t-t_{0}\right) \\
& u_{C_{3}}(t)=U_{i n}-\frac{I_{P_{0}}}{2 C_{r}}\left(t-t_{0}\right)
\end{aligned}
$$

(3) Mode $3\left[\mathrm{t}_{1}, \mathrm{t}_{2}\right]$

At $t_{2}, D_{3}$ opened, at the same time, open $Q_{3}$, and $Q_{3}$ is zero voltage turning. The primary side circuit of $\mathrm{D}_{3}, \mathrm{C}_{\mathrm{b}}$, transformers, $\mathrm{Q}_{4}$. At the same time there are two secondary current loop , one current loop $\mathrm{L}_{6}, \mathrm{R}, \mathrm{Q}_{6}$, current freewheel , another current loop for the $\mathrm{C}_{5}, \mathrm{~L}_{5}, \mathrm{R}$, so this loop until the diode $\mathrm{D}_{5}, \mathrm{C}_{5}$ discharge guide . At this point turn on $\mathrm{Q}_{5}$, the $\mathrm{Q}_{5}$ is zero voltage turning on. At this point $\mathrm{Q}_{5}, \mathrm{Q}_{6}$ are turned on simultaneously, the transformer secondary is shorted, so blocking capacitor $\mathrm{C}_{\mathrm{b}}$ voltage is applied to the leakage inductance of all, the primary current starts to decrease linearly. At $t_{2}$, primary current drop to zero. $\mathrm{U}_{\mathrm{AB}}=0, \mathrm{U}_{\mathrm{A}}=0, \mathrm{U}_{\mathrm{B}}=0$.

The primary current drops to zero at $\mathrm{t}_{2}$. The continuing period is:

(4) Mode $4\left[t_{2}, t_{3}\right]$

$$
t_{12}=\frac{L_{k} I_{P_{0}}}{U_{C b}}
$$

In this mode, the primary current $i_{p}=0$, there are two sides of the transformer freewheeling circuits, one for the $\mathrm{L}_{5}, \mathrm{Q}_{5}, \mathrm{R}$, another one for the $\mathrm{L}_{6}, \mathrm{C}_{6}, \mathrm{R}$-wheeling until $\mathrm{D}_{6}$ turns on, off $\mathrm{Q}_{6}, \mathrm{Q}_{6}$ zero voltage is turned off . $\mathrm{U}_{\mathrm{AB}}=\mathrm{U}_{\mathrm{Cb}}, \mathrm{U}_{\mathrm{A}}=0, \mathrm{U}_{\mathrm{B}}=-\mathrm{U}_{\mathrm{cb}}$.

(5) Mode $5\left[\mathrm{t}_{3}, \mathrm{t}_{4}\right]$

At $t_{3}$, due to the primary current is zero , so the $Q_{4}$ is off, the $Q_{4}$ is with zero current shutdown mode, after small period of delay, opening $\mathrm{Q}_{2}$, due to the presence of leakage current cannot be mutated, so $\mathrm{Q}_{2}$ is zero current turn . $\mathrm{U}_{\mathrm{AB}}=-\mathrm{U}_{\mathrm{in}}, \mathrm{U}_{\mathrm{A}}=0, \mathrm{U}_{\mathrm{B}}=\mathrm{U}_{\text {in }}$.

(6) Mode $6\left[\mathrm{t}_{4}, \mathrm{t}_{5}\right]$

At $t_{4}$, the primary energy began to secondary output while blocking capacitor $C_{b}$ to reverse charge. At $t_{5}$ off $Q_{3}$, from the beginning of the next half cycle $\left[t_{5}, t_{10}\right]$, equivalent to the above-mentioned period $\left[\mathrm{t}_{0}, \mathrm{t}_{5}\right]$. Blocking capacitor voltage reaches its maximum at the time $\mathrm{t}_{6}$, therefore: 


$$
U_{b_{0}}\left(\mathrm{t}_{6}\right)=U_{b_{0}}\left(\mathrm{t}_{5}\right)-2 \frac{C_{r} U_{i n}}{C_{B}}=U_{C_{0}}-\frac{I_{P_{0}}}{C_{b}} t_{45}-2 \frac{C_{r} U_{i n}}{C_{b}}=-U_{C_{0}}
$$

Due to $C_{r}$ and $C_{b}$, so

$$
U_{C_{0}}=\frac{I_{P_{0}}}{2 C_{b}} t_{45}
$$

\section{Conditions of Achieving Soft Switching and Synchronous Rectifier Drive Design}

(1) Achieving ZVS conditions for the leading leg switches

To ZVS conditions for the leading leg switches, the transformer leakage inductance and the capacitor resonance process must have sufficient energy to charge the capacitor in all consumed ( including the transformer primary winding parasitic CTR), thus it must meet the following formula:

$$
E>\frac{1}{2} C_{r} U_{i n}^{2}+\frac{1}{2} C_{b} U_{i n}^{2}+\frac{1}{2} C_{T R} U_{i n}^{2}
$$

During the period of achieving ZVS, as the current of primary side of the transmer remains the same and approximately equal to a current source. Therefore, the ZVS can be realized as long as the dead time satisfy the following formula.

$$
T_{d}>\frac{2 C_{r} U_{i n}}{I_{1}}
$$

(2) Conditions for the lagging leg switches to realize ZCS

From the analysis of principles for converter, the conditions for the lagging leg switches to realize ZCS is the primary current should be reduced to 0 before the lagging leg switches is on, so $t_{12}$ is:

$$
t_{12}=\frac{2 L_{k} C_{b}}{t_{45}}=\frac{4 L_{k} C_{B}}{D T}
$$

$\mathrm{D}$ is the duty factor and $\mathrm{T}$ is the period in the above formula

(3) conditions for synchronous rectification to achieve soft switching and driving

In the case of synchronous rectifier with heavy loads, if the conventional hard-switch, then the switch loss will be great which will cause a great heat on switch tube, it will cause not only secondary rectification efficiency is low, but also make the life of the switch reduced. So the best solution is to make the synchronous rectifier switch work in conditions of the soft-switching state, it will not only reduce the loss, but also to increase the service life of the switch.

In this paper, the parallel resonant secondary inductance and capacitance of the switch, the shunt capacitance voltage release to zero, so that the natural anti-parallel diode conduction, to achieve synchronous rectifier switch tube ZVS. In an example $\mathrm{Q}_{5}, \mathrm{Q}_{5}$ is driven by the drive waveform to $\mathrm{Q}_{1}$ reverse delay, delay time of the dead time plus ultra forearm $L C$ resonant time. Therefore, the delay time $\mathrm{T}_{5}$ is:

$$
T_{5}=T_{D 12}+\frac{\pi}{2} \cdot \frac{1}{\sqrt{\frac{1}{L_{5} C_{5}}-\frac{R^{2}}{4 L_{5}^{2}}}} \geq \frac{2 C_{1} U_{\text {in }}}{I_{P}}+\frac{\pi}{2} \cdot \frac{1}{\sqrt{\frac{1}{L_{5} C_{5}}-\frac{R^{2}}{4 L_{5}^{2}}}}
$$


Synchronous rectification side MOSFET driving waveform is ultra forearm drive waveform to be inverted and delayed, super signal after opto isolated forearm after a RC delay circuit, the delay time parameters are:

$$
\tau=-\mathrm{R} \cdot \mathrm{C} \cdot \ln \left(\frac{E-V}{E}\right)
$$

After comparison with standard $5 \mathrm{~V}$ voltage comparator output goes back into after the synchronous rectifier MOSFET driver chips. As shown in Figure 3.

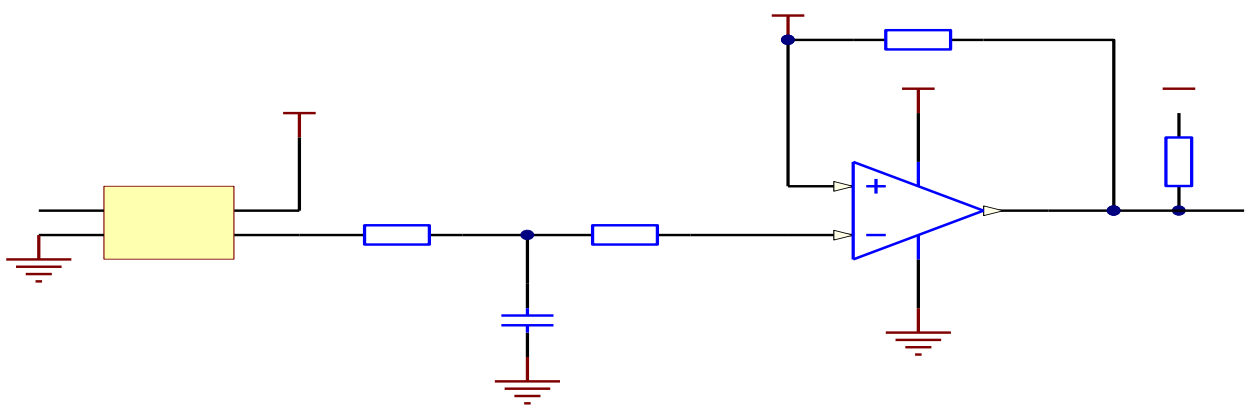

Figure 3. Synchronous Rectifer Circuit

\section{Simulation and Analysis}

In order to verify the correctness and feasibility of the control method, simulation analysis was carried out saber the simulation model is shows in Figure 4. Input voltage is $530 \mathrm{~V}$, output power is $4.8 \mathrm{KW}(48 \mathrm{~V} / 100 \mathrm{~A})$.

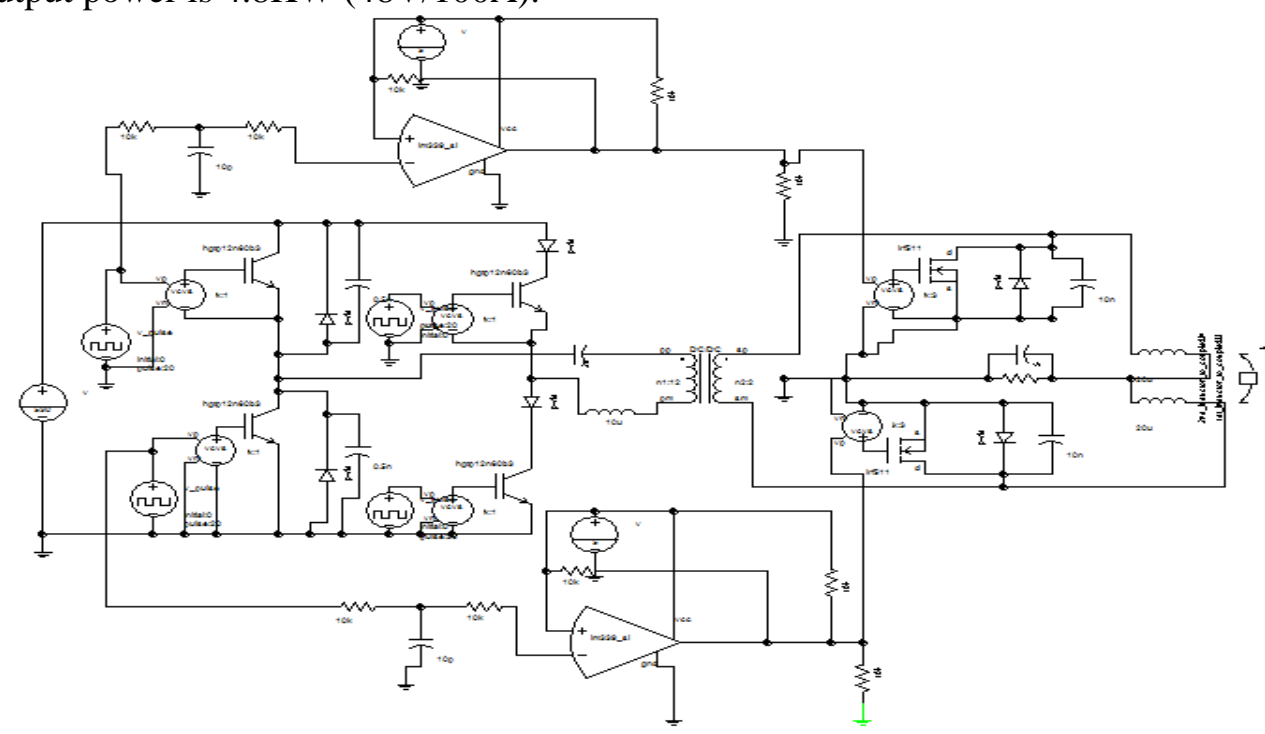

Figure 4. Saber Simulation Circuit

From Figure 5, by means of the solid line that is $\mathrm{V}_{\text {ce }}$ of $\mathrm{Q}_{5}$ waveform and dashed that is Vge of $\mathrm{Q}_{5}$ waveform, ZVS condition for leading leg switches is shown in Figure (a). ZCS condition for lagging leg switches is shown in Figure (b), drive waveform of $\mathrm{Q}_{4}$ is the solid line, LC by $\mathrm{Q}_{4}$ of current waveform is the dashed line. In addition, ZVS condition for synchronous rectifier is shown in Figure (c), and the solid line is Vds of $Q_{5}$, dashed line is Vgs of $\mathrm{Q}_{5}$. Load output is shown in Figure (d). 


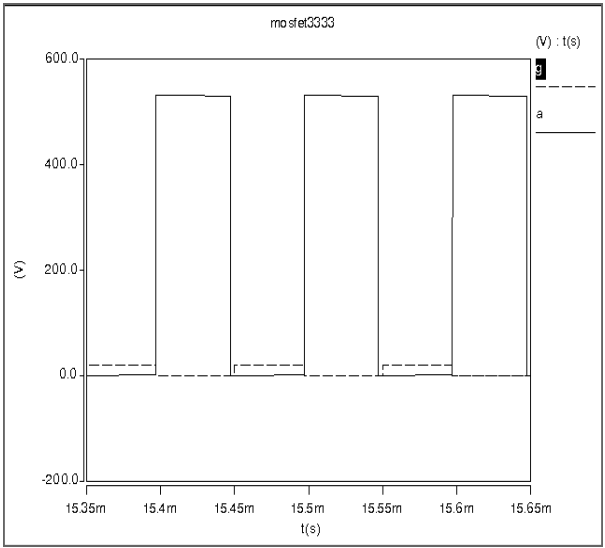

(a) ZVS Condition for Lagging Leg Switches

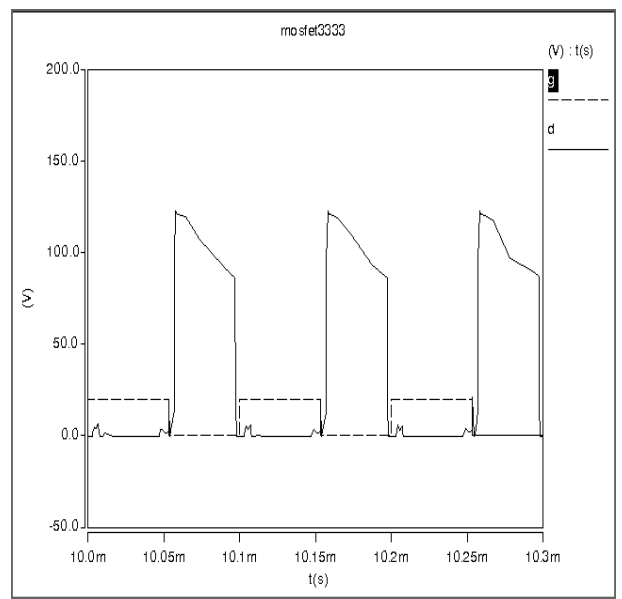

(c) ZVS Condition for Synchronous Rectifier

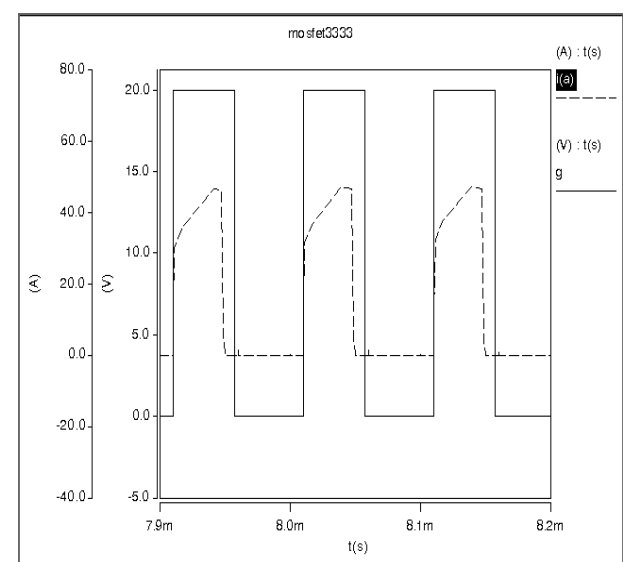

(b) ZCS Condition for Lagging Leg Switches

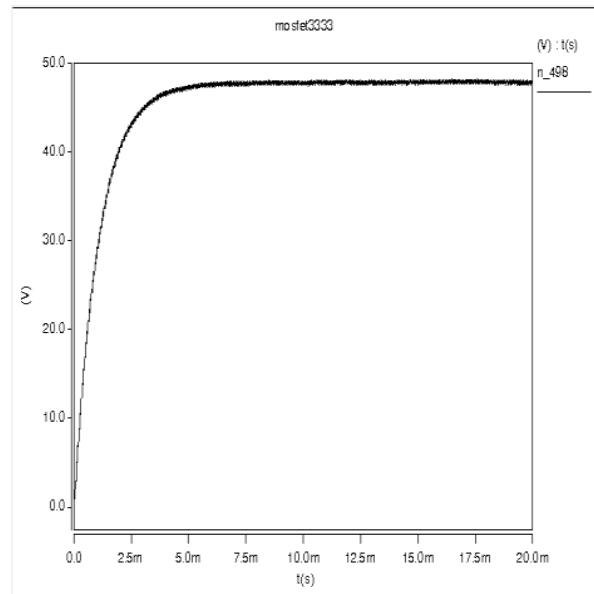

(d) Load Output Voltage

Figure 5. Experiment Simulation Waveforms

\section{Experiment Result}

To verify the effectiveness of the proposed converter, prototype of the proposed converter is designed with following specifications. Input voltage is $380 \mathrm{~V}$ and output voltage is $48 \mathrm{~V}$.Output power: $4.8 \mathrm{KW}(48 \mathrm{~V} / 100 \mathrm{~A})$. Switches are FGA25N120. The ratio of transformer $\mathrm{n}=5.5, \mathrm{~L} 5=\mathrm{L} 6=$ $20 \mathrm{uH}$, blocking capacitor $\mathrm{C}_{\mathrm{b}}=2 \mathrm{uF}$. As shown in Figure 6, experimental waveforms of the proposed converter, ZVS condition for leading leg switches are achieves, including the waveform 1 for Vce and the waveform 2 for Vge, the same as (a) corresponding to simulation and experimental results seen in Figure 5. ZCS condition for lagging leg switches is shown in Figure 7, in where the waveform 1 is Ic and the waveform 2 is Vge, Corresponding to Figure 5 (b) simulation and experimental results can be seen. ZVS condition for synchronous rectifier is shown in Figure 8, in where the waveform 1 is Vge, the waveform 3 is Vce, the same as (c) corresponding to simulation and experimental results seen in Figure 5.

At the same time to test the whole efficiency of the proposed converter in this paper, with traditional PSFB converter through the contrast analysis of figure 9 is given the same input and output parameters of both the overall efficiency contrast curve. Can be seen from the figure 9 , the overall efficiency of the proposed converter than traditional PSFB converter have certain to improve under different load in this paper. 


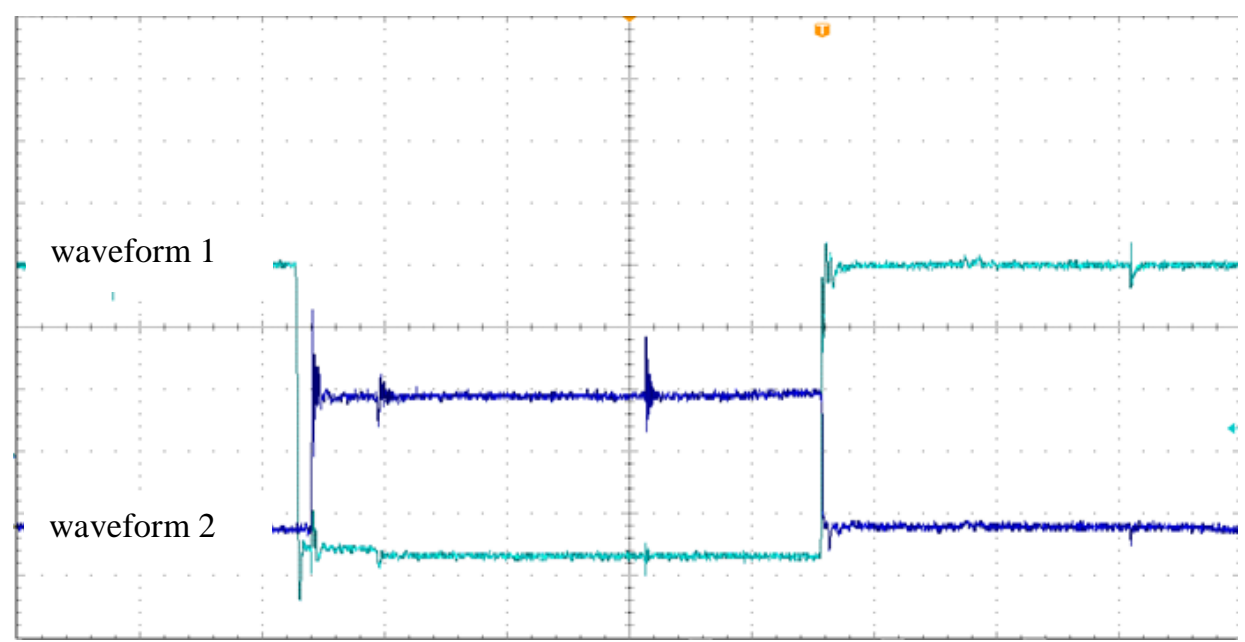

Figure 6. ZVS of Leading Leg Switches

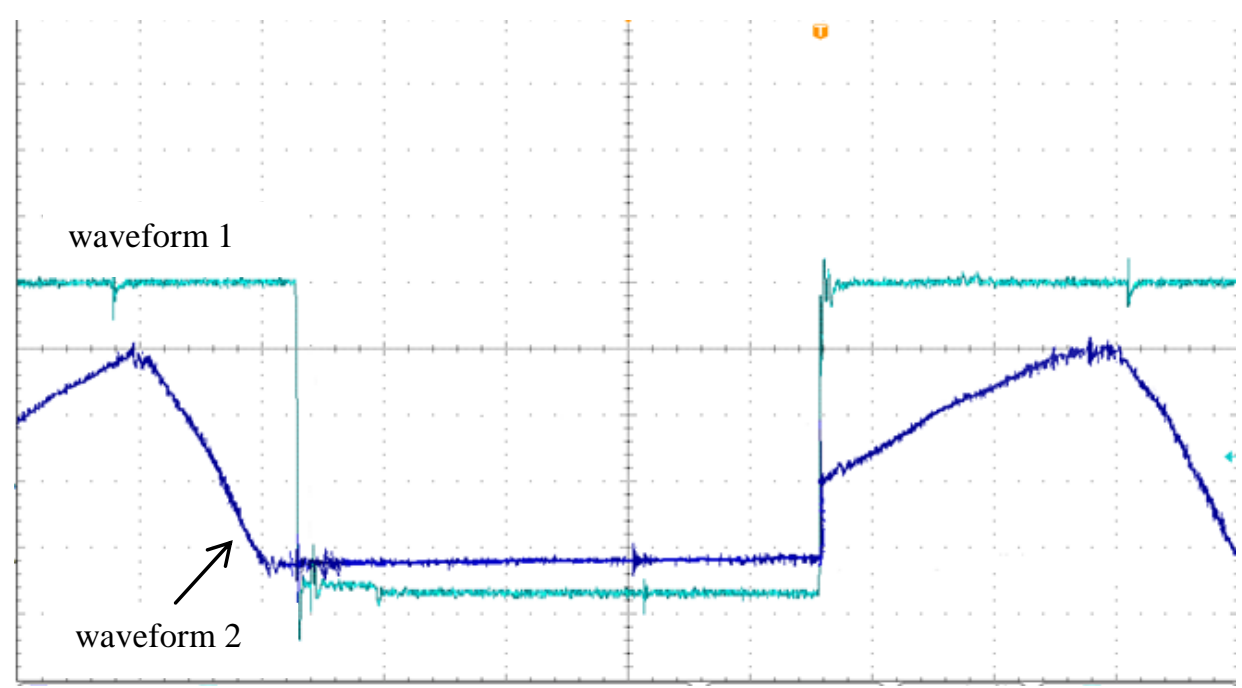

Figure 7. ZCS of Lagging Leg Switches

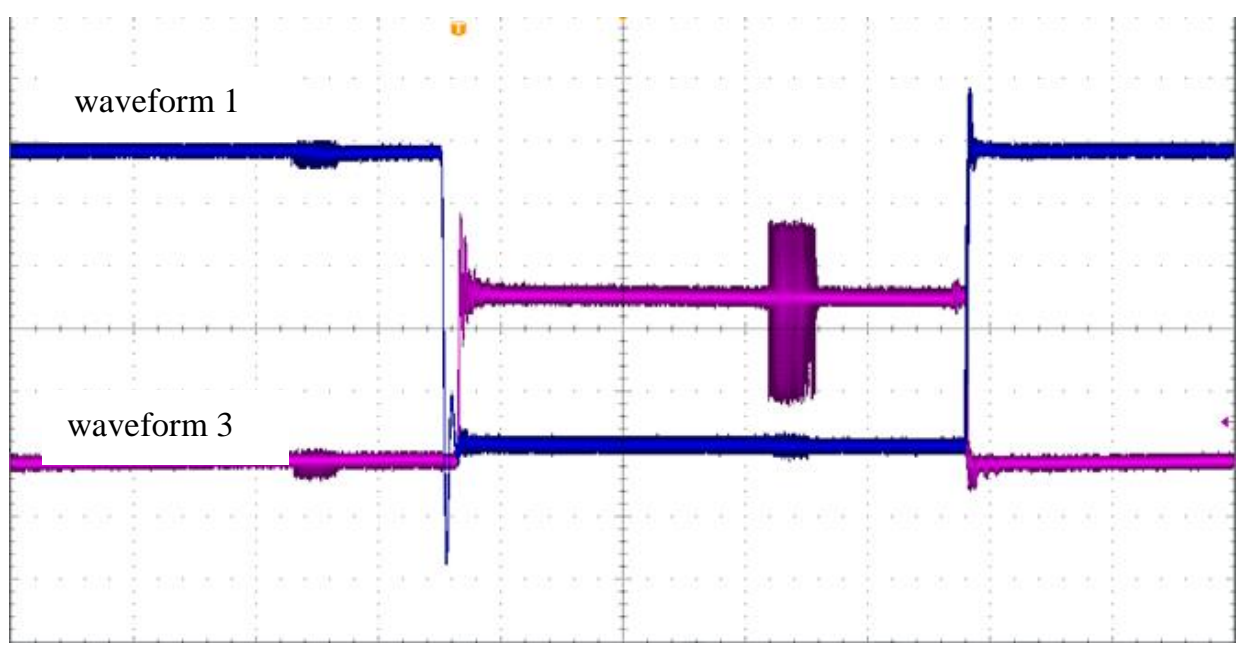

Figure 8. ZVS Condition for Synchronous Rectifier 


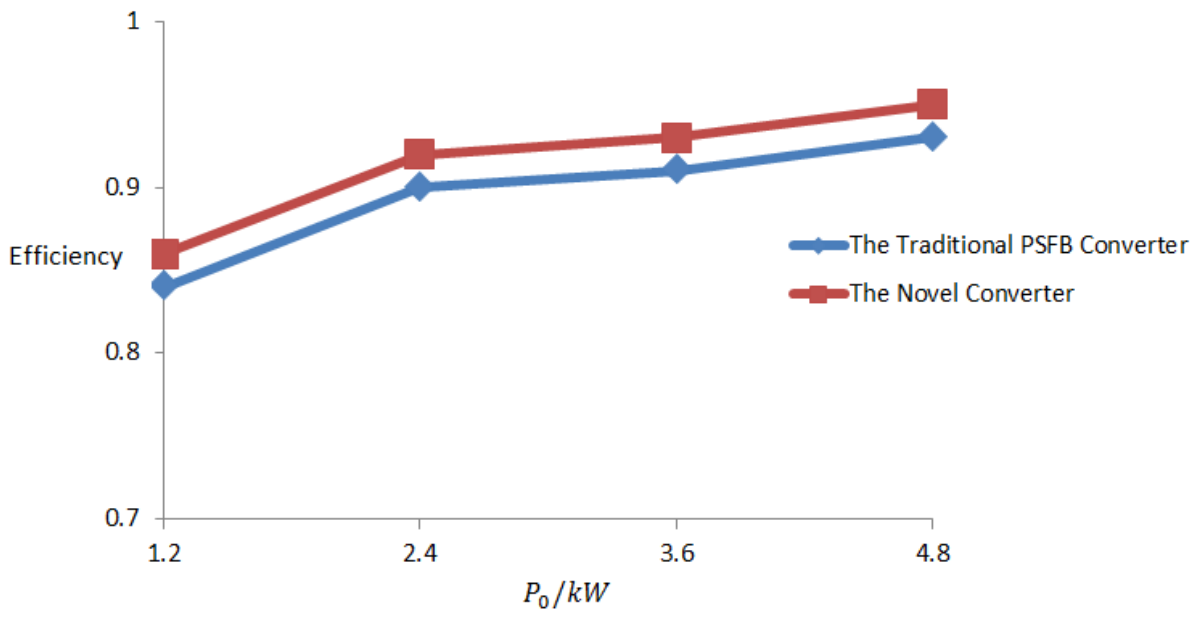

Figure 9. Curves of Efficiency

\section{Conclusion}

In this paper, a novel control method based on ZVZCS converter synchronous rectifier is presented, using the topology of the lag bridge arm concatenated diode: The seconary side rectifier drive signal get the opposite of the two PWM waveform from advanced arms and add proper delay, not only achieve the full bridge ZVZCS, but also carry out the sychronous rectifer ZVS. Simulation and experimental results show that this control method can enable all switches of the converter to work within large scope of soft switch which will improve the efficiency of the converter.

\section{Acknowledgements}

This work is supported by Heilongjiang Natural Science Foundation (E201302).

\section{References}

[1] S. Sato, S. Moisseev and M. J. Nakaoka, "A Novel Synchronous Rectifiers Based ZVS-PWM DC-DC Power Converter with Extended Soft-Switching Operation Range”, IEEE, (2003), pp. 19-23.

[2] W.-S. Zhou, R.-f. Hu, Q. Zhou and L.-m. Sheng, "Research on a DC/DC Converter using Current Double Synchronous Rectifier and Active Clamp Circuit”, Journal of Tsinghua University (Science and Technology), vol. 3, no. 38, (1988), pp. 77-81.

[3] L.-d. Xu, "A ZVS Phase-shift Full Bridge Converter with Current Double and Synchronous Rectifier", Power supply to the 10th annual meeting and new energy development and academic conference on power electronics in Zhejiang province.(2006) October; Zhejiang, China.

[4] J.-h. Zhang, W. Sun and S.-h. Sun, "Research on ZVS Full Bridge Converter with Current Double and Synchronous Rectifier", Power Electronics, vol. 2, no. 44, (2010).

[5] C.-f. Lv, C. Han and Z.-w. Liu, "Analysis and design of phase-shift full bridge zero-voltage zero-current switching DC-DC regulated power supply", Chinese Journal of Power Sources, vol. 7, (2013).

[6] C.-1. Ouyang and Y.-g. Yan, "Modeling Analysis of Synchronous Rectifier Buck Converter in Discontinuous Conduction Mode", Transactions of China Electrotechnical Society, vol. 6, no. 17, (2002), pp. 53-58.

[7] Y.-g. Yan and X.-b. Ruan, "The DC switching power supply of soft switch technology", Science Press, Beijing (2003).

[8] X.-j. Zhang, G.-n. Liu, Y.-j. Wang and D.-g. Xu, "Bidirectional DC/DC converter control model analysis based on super capacitor", ELECTRIC MACHINES AND CONTROL, vol. 11, no. 17, (2013), pp. 89-96.

[9] D.-x. Liu, Z.-g. Wu, Y.-m. Li and H. Huang, "J. Study on ZVZCS Phase-Shift Full-Bridge DC Converter with Current-Double Rectifier", Telecom Power Technology, vol. 27, no. 5, (2010).

[10] L. Wu, Y.-z. Zhang, Z.-x. Li, P. Wang, Y.-h. Li and Z.-g. Liu, "A control strategy of isolated bidirectional full bridge DC/DC converter", ELECTRIC MACHINES AND CONTROL, vol. 12, no. 16, (2012), pp. 21-27. 